\title{
O DESENHO: UM PROCESSO DE ENSINO, APRENDIZAGEM E DESENVOLVIMENTO DO PROCESSO CRIATIVO
}

Marcia Moreno ${ }^{1}$

Resumo: Esta pesquisa visa justificar a importância do desenho como linguagem para o desenvolvimento do processo criativo do sujeito, refletindo, inclusive, essa ampliação da criatividade, na fase adulta. Sendo assim, no decorrer do texto, são apresentadas algumas situações/possibilidades, trazidas por alguns autores bem como da minha própria trajetória como docente.

Palavras-chave: criatividade; desenho; educador; educando. 


\section{Introdução}

Essa pesquisa surgiu a partir dos estudos realizados no decorrer da trajetória docente, onde um dos principais conteúdos que eu tenho trabalhado no ensino é o desenho e, posteriormente, o reflexo dessa atividade no que se refere à criatividade e ao sujeito criativo.

Como suporte teórico, entre vários investigados, o mais significativo foi o livro da autora Cox (2001), onde ela traz detalhadamente os processos e resultados do desenho aplicados em sala de aula em distintos continentes, mostrando a influência do adulto na construção do processo criativo da criança, tendo como instrumento, o desenho.

Outro assunto importante aqui apresentado é quanto à criatividade e ao sujeito. Há uma apresentação quanto a esse processo no decorrer do desenvolvimento do sujeito e de qual reflexo terá quando adulto. E mais uma vez é citada a importância do professor para a construção do indivíduo, incluindo também o meio social, tendo um papel fundamental os pais, que são os mediadores iniciais desse processo.

\section{Embasamento teórico}

\section{A criatividade e o sujeito}

Segundo a autora Ostrower (1987), criar é basicamente formar, são novas relações estabelecidas pela pessoa e o ato criador. Compreende a capacidade que o ser humano tem de significar as coisas, sendo ele um "fazedor", porque é capaz de relacionar e configurar as suas experiências de vida, dando significados.

Nós vivemos entre formas e estímulos que recebemos a todo o instante. Alguns, relacionamos e percebemos, pois, estão vinculados a nós mesmos e sobretudo com uma atitude do nosso ser mais íntimo, constituindo uma maneira específica de interpretar os fenômenos, buscando significados que trazem a motivação de criar, sentindo a necessidade de comunicar-se com os outros; só assim podemos crescer 
enquanto seres humanos, coerentemente, ordenando, dando formas e criando.

No âmbito conceitual ou intelectual, os processos criativos articulam-se principalmente através da sensibilidade, sendo ela patrimônio de todo ser humano, ainda que em áreas sensíveis diferentes. O ser humano nasce com um potencial de sensibilidade, que é um canal ou porta de entrada das sensações, ligando-o de imediato a tudo que acontece em seu entorno.

O bebê ao nascer já é portador do potencial de consciência, enquanto dorme ele vai ordenando certas sensações e gradualmente vai organizandoas. Ele vai crescendo e adquirindo novas experiências; constata que quando chora por estar molhado é atendido, portanto começará a usar desta descoberta para ficar seco e posteriormente para ganhar colo. Experimentará sensações de cheiros ou movimentos, começa a significar.

Adquirindo a significação e começando a interagir mais intensamente com o meio, o bebê transfere para o consciente e inconsciente essas informações e cria símbolos. É o desenvolvimento do processo de crescimento interno, onde criamos várias formas de viver e nelas o nosso fazer.

A imaginação produtiva ou criadora, por sua vez, refere-se à capacidade de invenção, de criação de formas e figuras. É algo que introduz o novo, constitui o inédito, a posição de novos sistemas de significados e de significantes, presentifica o sentido. Esse imaginário passa a ser, especialmente, o motor de criação.

Para o autor Busse (apud ALENCAR,1993), a criatividade é tratada como um conceito relativo, sendo denominado um produto criativo, considerando o momento histórico, apresentando diferentes níveis de criatividade, o nível menos e o mais elevado que tem uma identificação de um grau maior de transformação. Segundo o autor, a criatividade "[...] implica emergência de um produto novo" (p. 15), sendo ela uma ideia ou uma invenção original, ou até mesmo a reelaboração e aperfeiçoamento de um produto já existente, mas para essa criatividade ser aceita é necessário que a ideia seja apropriada a uma determinada situação.

Existem pensamentos de que a criatividade é um dom divino, ou então, de que existem pessoas seletas para a criatividade. Ou ela é ou 
não criativa, desconsiderando que, na realidade, o que existe são pessoas mais criativas e outras menos. Essa habilidade criativa pode ser desenvolvida e aprimorada com a utilização da prática e do treino, pois, além de "iluminação" e de inspiração, precisamos de muito trabalho, prática, atitude criativa e padrões perfeccionistas.

Analisando a criatividade nos artistas e cientistas, nos quais ela é mais evidente, verificou-se que ela não é resultado de uma inspiração súbita, mas sim, de muito trabalho e esforço por parte do indivíduo (GARDNER,1996). Para estimular a criatividade existem vários programas que visam remover as barreiras que inibem ou bloqueiam essa manifestação nos "menos favorecidos".

Existem os processos cognitivos ligados aos processos psicológicos que envolvem o conhecer, compreender, perceber, aprender, etc. Segundo o autor, eles estariam presentes nos vários estágios do processo criativo, já que a criatividade é desenvolvida na área em que o indivíduo está atuando, levando-o a apresentar originalidade ao apresentar respostas incomuns e remotas.

Mas antes dessa apresentação há uma elaboração, e esta é dada a partir de esboços, e segundo o autor, esse aspecto pode ser observado com intensidade nas produções dos artistas plásticos que, após vários esboços é que chegam a uma obra concluída. Para isso, o artista deve ter conhecimento dos materiais e técnicas; assim como os bons escritores, estar "além" da imaginação; um crítico, boas habilidades avaliativas e assim por diante.

Gardner (1997) comenta que há uma necessidade essencial do sujeito desenvolver habilidades técnicas. Encontramos essa afirmação também no livro de Dalto (1993), quando ela entrevista vários profissionais de diferentes áreas de atuação quanto ao desenvolvimento criativo. Na maioria das respostas houve a confirmação de que, para um sujeito ser criativo, independentemente da área, há a necessidade da habilidade/conhecimento técnico e de muito "treino", repetição de exercícios, de atividades.

E Alencar (1993) afirma que as escolas devem dar maior atenção para a criatividade de seus alunos, porém, não há uma garantia de que uma criança criativa venha a ser um adulto criativo. As escolas foram criticadas em 1967 pelo fracasso em estímulos à criatividade do aluno, 
condenaram à pressão, à submissão, ao comodismo e ao hábito compulsivo de trabalho, além da repetitividade de exercícios que acabam prejudicando o pensamento espontâneo e intuitivo.

No processo criativo há também a preparação, fase em que o "criador" pesquisa, anota, discute, explora, aponta os pontos positivos e negativos, dá-se como um investigador. Dessa forma, ignora-se a ideia de que o artista plástico, escritor e outros produzem num momento de inspiração ou de iluminação. Ele produz após um intenso processo operatório, tendo esse processo a duração de semanas e até mesmo anos. Quando nos dedicamos a desenvolver um tema, tanto para a escrita quanto para a ilustração, devemos passar o tempo todo questionando o tema, mesmo já estando em processo de desenvolvimento.

Já a iluminação, momento de grande importância é o instante em que surge a ideia, a solução para o problema. Esse processo ocorre após um intenso período de preparação, podendo surgir em momentos intensos de alegria, levando o indivíduo a trabalhar por longos períodos, interrompendo no momento de esgotamento de ideias ou com a exaustão. Mas a iluminação pode também se manifestar no momento em que o indivíduo estiver totalmente desligado da procura da solução ou inspiração. Um exemplo "clássico" é o de Einstein, que tinha as suas melhores ideias enquanto se barbeava.

Para os estudiosos, é de extrema importância o abandono do pensamento lógico, pois este bloqueia a criatividade, interrompendo a formulação de ideias. Somente num segundo momento é que deve ocorrer a elaboração em que as ideias ficam sujeitas a uma avaliação lógica.

Ocorre muitas vezes das pessoas acordarem no meio da noite com várias ideias, bloqueando o passado e o futuro, vivendo somente com o presente. Essa fase de inspiração da criatividade é chamada de integração "self”. A criatividade é, também, com um trabalho sistemático e conhecimento acumulado durante muitos anos, mas com aceitação dos próprios impulsos.

Outro grande fator que influência a criatividade é o meio social do indivíduo, por exemplo: valores familiares, personalidade e características cultivadas. Os fatores tanto intrapessoais quanto os interpessoais têm importância significativa no desenvolvimento criativo do indivíduo, refletindo na sociedade, pois, a criatividade não depende somente dos 
esforços do indivíduo. De Masi (2005) afirma em seu livro que: “[...] depois de Cristo, a criatividade individual é somente uma abstração ou um delírio de onipotência. Neste campo, mais do que nunca, é válida a frase de Thomas Merton: 'Nenhum homem é uma ilha'” (p.47).

Para que o social possa ter um papel completo na evolução da criatividade, deve favorecer a criação por parte do indivíduo, dandolhe chances para obter experiências em inúmeras áreas, evitando assim a limitação de conhecimento.

Para que ocorra o desenvolvimento da criatividade, os estímulos devem dar-se no lar, no convívio social e, posteriormente, nas escolas, pois são necessárias condições adequadas para o desenvolvimento da criatividade. Sabe-se que as manifestações criativas são dadas em pessoas que apresentam um conjunto de valores, atitudes, interesses, motivações e traços de personalidade, que proporcionam ao indivíduo um pensamento independente e flexível e o uso da imaginação.

Em muitos casos, os estímulos na criança são bloqueados por comportamentos rígidos dos pais. Eles favorecem a exploração da criatividade quando estes têm um relacionamento não possessivo com seus filhos, e cooperam também para a independência, autoconfiança e até mesmo para a inteligência das crianças.

Experiências vividas nos primeiros anos na escola, também são de fundamental importância. A influência do professor facilita a formação de imagens positivas ou negativas de si mesmo pelo aluno. O simples fato de um professor chamar o aluno pelo próprio nome, cumprimentá-lo, elogiá-lo, propicia-lhe um sentimento de valor pessoal.

A seguir teremos alguns relatos de como nós professores poderemos melhor "orientar" os nossos educandos quanto ao processo de ampliação da capacidade de desenhar e criar, levando m conta sobretudo os estudos de Maureen Cox (2001).

\section{O desenho e a criança na escola: algumas possibilidades}

Foi em torno de 1880, num dia chuvoso que Corrado Ricci, ao buscar abrigo em uma viela coberta, percebeu na parede a presença de alguns rabiscos que lhe chamaram a atenção. "Viu alguns dese- 
nhos encantadores e um tanto desajeitados que qualquer pessoa reconheceria como feitos por mão infantil" (COX, 2001, p.02). A partir daí, Ricci se envolveu por inteiro nos estudos sobre o desenho infantil, lançando sete anos depois seu livro A arte das Crianças Pequenas.
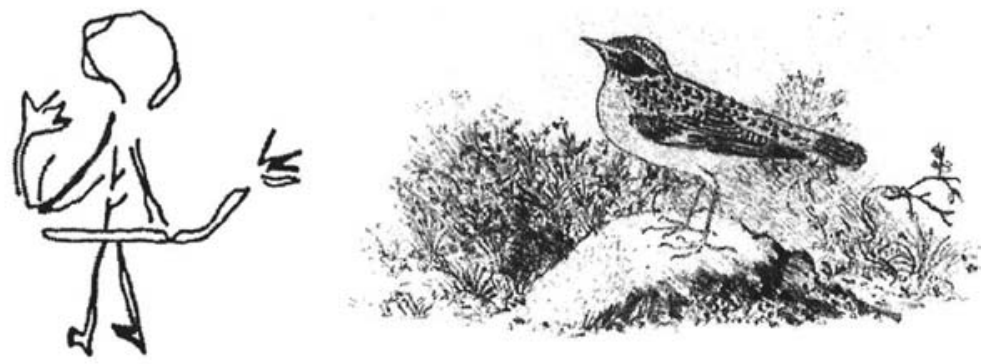

Figura 01: Acredita-se que o primeiro desenho tenha três mil anos e o TangeAsno foi desenhado em 1829, por Emily Brote, aos 10 anos de idade.

Fonte: Cox, 2001

Antecedendo a esse acontecimento de Ricci, o então filósofo e educador Jean-Jacques Rousseau (1712-1778) já considerava a infância distinta e importante quanto ao desenvolvimento do sujeito em um processo evolutivo à idade adulta (não mais como adultos em miniatura). Elas passam a ser vistas como sujeitos únicos e que têm sua maneira própria de pensar e de resolver as situações diferentemente dos adultos.

Segundo Moreno (2005), a agilidade e a transitoriedade natural do desenho em geral é acompanhada pela flexibilidade e rapidez mental, que integram a percepção e o pensamento. "Existe a vontade de uma representação como também existe uma necessidade de trazer à tona desejos interiores, comunicados, impulsos, emoções e sentimentos" (p.50).

Quando solicitadas a desenharem algo na escola (principalmente), onde o professor leva em consideração a importância do desenho para o desenvolvimento da criança, bem como o próprio entusiasmo, utiliza desses fatores para a elaboração de atividades artísticas. A única preocupação da criança é quanto à intenção de promover no adulto a percepção da forma em si, o seu real significado, principalmente 
entre os oito anos de idade. "Porém, embora se mostrem dispostos e desinibidos em desenhar, as crianças se preocupam extremamente com que os objetos de seus desenhos possam ser identificados" (COX, 2001, p.04).

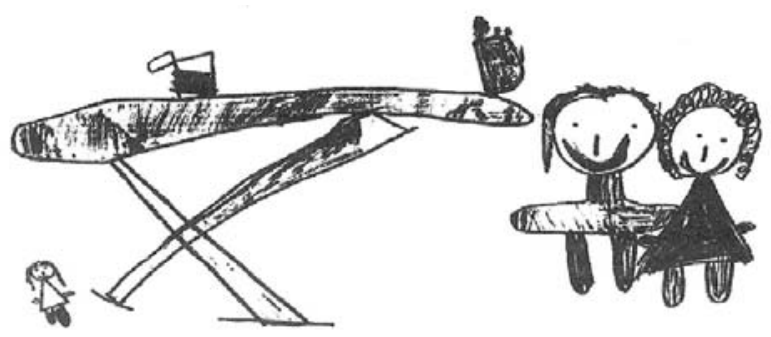

Figura 02: Passando a Roupa, de Amy, cinco anos e oito meses. Fonte: Cox, 2001

Já ao pedirmos para o adulto para realizar um desenho, a grande maioria afirmará não saber, inclusive se esquivando, com certo embaraço e desleixo para como seu desenho. "Embora não se possa esperar que seus desenhos se equiparem aos dos grandes artistas, poderíamos esperar, pelo menos, certo grau de competência e habilidade" (p.5).

Cox (2001), assim como outros autores, afirma que as Artes Plásticas são importantes meios para o desenvolvimento criativo das crianças, mas muitas vezes o adulto acaba, através de algumas atitudes/ situações, "sufocando" o processo criativo. "A ideia de que o professor possa mostrar a uma criança como desenhar algo ou ao menos 'conversa' sobre como algo poderia ser desenhado, é descartado como excessivamente direcionado pelos professores" (p.7). Essa atitude, muitas vezes, pode fazer com que a criança adote os estereótipos fornecidos pelo professor.

\section{Rabiscando}

No momento em que a criança passa a explorar o desenho (pois ela percebe que consegue produzir algo com o lápis), observa que 
realiza vários tipos de traços, ampliando seu repertório. Esse repertório pode ser visto no quadro que apresenta onze "componentes".

Segundo Hsuan-An (1997), o desenho é tratado como uma linguagem entre tantas outras nas Artes Visuais: "Desenhar é um processo da ação criadora que se desenvolve mediante a percepção, reflexos intuitivos e intelectuais e controle do material" (p.26).

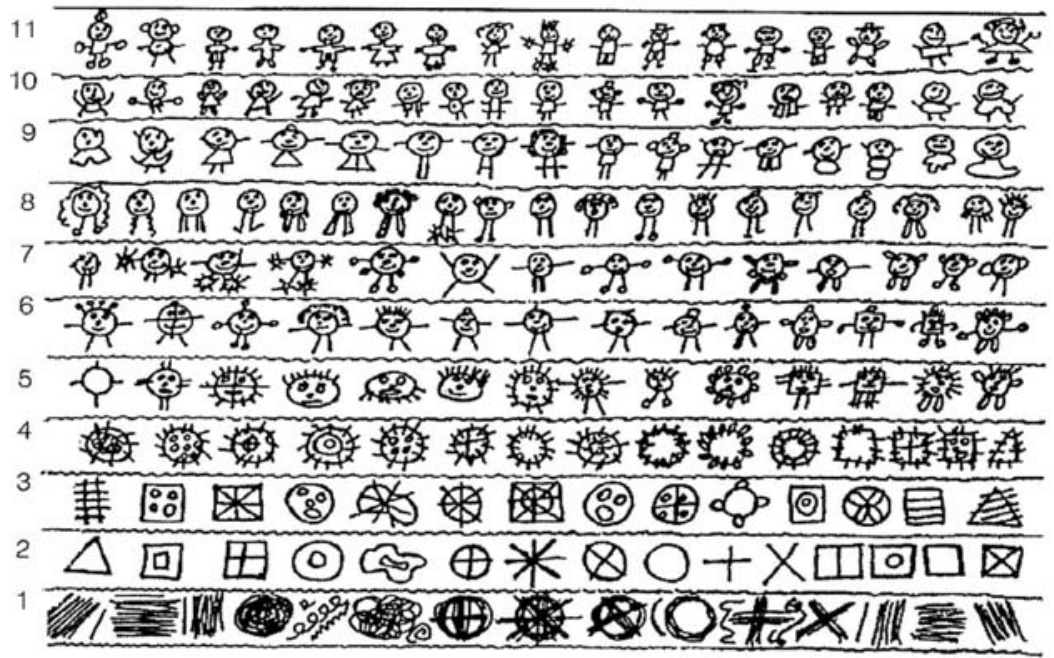

Figura 03: Rhoda Kellogg é de opinião que os rabiscos básicos das crianças evoluem para formas mais complexas que, por sua vez, transformam-se em figuras humanas. A evidência desse desenvolvimento não é no entanto, muito forte. Fonte: Cox, 2001

No quadro acima são demonstrados alguns processos evolutivos do desenho infantil até chegar à figura representativamente humana. Porém, esses exemplos não são regras. A autora traz exemplos, em que foi solicitado a algumas crianças para representarem a figura humana e quase $40 \%$ das crianças de dois anos e $80 \%$ de três produziram os desenhos sem passar pela sequência vista anteriormente. Não é uma regra, é apenas uma possibilidade vir a ter essa sequência "evolutiva" dos traços.

Sem mesmo saber construir as formas em si, as crianças têm a real noção do "fazer desenhos". Elas "adquirem também uma boa 
noção de como as formas devem ser dispostas na página: por exemplo, os olhos lado a lado e acima do nariz, e este, por sua vez, acima da boca" (COX, 2001, p.23). Será que precisamos ficar insistindo com o "homem palito" com as crianças? Claro que não, as crianças são muito perceptivas até mais que os adultos. Temos como exemplo dessa afirmação (apresentado pela autora Cox, 2001), uma experiência de Bill Ives que solicitou as crianças de dois a três anos que construíssem, com pedaços de feltro, rostos, e o resultado foi muito satisfatório. A grande maioria construiu com coerência.

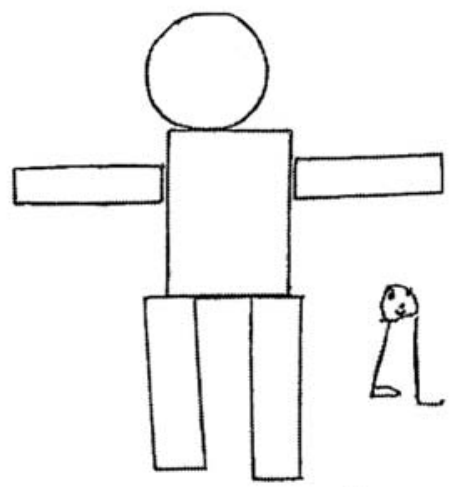

Figura 04: Robert, quatro anos e nove meses.

Fonte: Cox, 2001

Outra questão importante de se apontar é a respeito da nomenclatura dada pelas crianças para os seus próprios desenhos. A autora solicitou a sua filha Amy (dois anos e onze meses), que desenhasse uma pessoa, porém, após concluir seus rabiscos, a menina justificou ser um tronco com várias maçãs. Ocorre que, às vezes, as crianças vão desenhando e posteriormente é que passam a nomear seus rabiscos, como no exemplo trazido:

Em outra ocasião ficou surpresa e maravilhada com a forma que acabara de desenhar (Amy): 'Olhe! É um pássaro!' Disse então 'Está faltando o olho', e acrescentou um ponto. 
Em seguida, 'Eles têm pernas, não têm ${ }_{\complement}$ Cinco pernas!' Tendo desenhado a forma básica de um pássaro ela foi capaz de, intencionalmente, acrescentar-lhe suas outras partes (p.24).

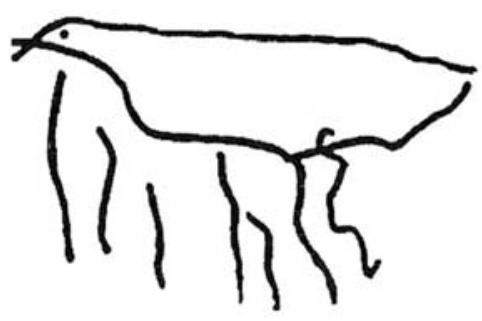

Figura 05: Um pássaro feito por Amy, aos dois anos e dez meses. Fonte: Cox, 2001

Quanto aos objetos tridimensionais, isso é outro fator que merece nossa atenção, pois o que é "oferecido" às crianças são formas, e não apenas linhas. Sendo assim, ela se questiona sobre como, através das linhas, que a natureza não lhes proporciona, vai poder representar através do desenho essas formas reais com o volume.

Para Arnheim (2000) "[...] as crianças observam com uma agudeza que faz os adultos ficarem envergonhados” (p.155). Há uma dedicação muito maior por parte delas quanto ao desenho e apresentam uma intensa concentração na atividade, se forem comparadas com pessoas mais velhas.

Durante o período de quatro a cinco anos, as crianças, ao desenharem pessoas, já apresentam a relação aproximada entre parte do corpo e números de dedos, mas não de modo correto. Gardner (1999) complementa: "No final dessa faixa etária as crianças exibem mapeamento digital ou numérico, no qual distâncias específicas, proporções e números são dominados e retidos" (p.138). Nesse período, a criança "desenha o que conhece em vez de o que vê" (p.161). 


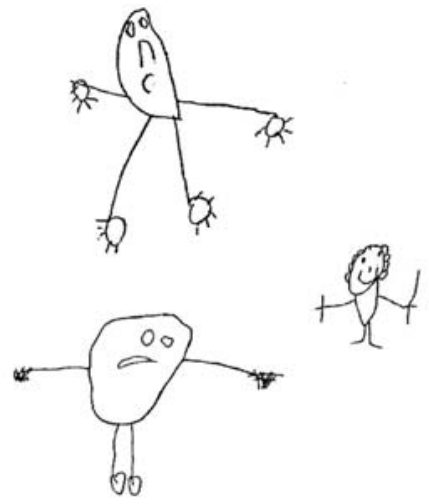

Figura 06: Alguns exemplos de representação das mãos.

Fonte: Cox, 2001

Com o passar da idade a criança deixa de fazer apenas linhas para realizar, então, as áreas/regiões, como forma de representar a volumetria. A linha é usada individualmente (agora) apenas para representar cabelos, cordões de sapato, cílios, etc.
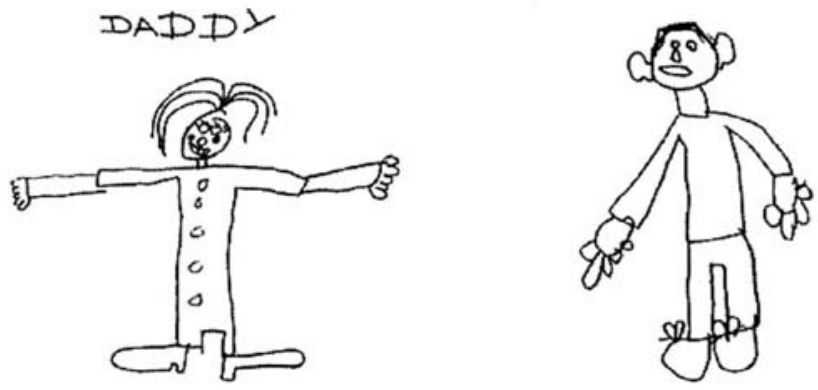

Figura 07: O pai de Samantha, cinco anos e dez meses. Auto retrato de Andrew, cinco anos e onze meses.

Fonte: Cox, 2001 

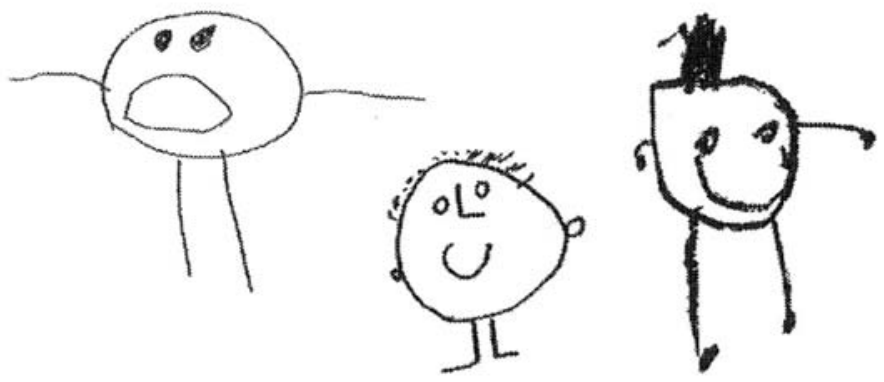

Figura 08: Desenhos realizados por crianças de três anos de idade. Fonte: Cox, 2001

A maneira como a criança desenha pode ser a manifestação de seu próprio estilo com um pouco de influência de outras crianças, bem como com muitas interferências de formas, podendo propagar até mesmo em uma sala inteira, tornando-se um estilo local ou, ainda, regional. É o que poderemos observar a partir das imagens seguintes:
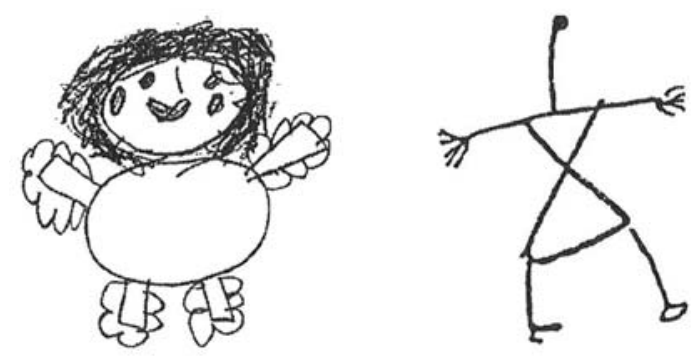

Figura 09: Primeiro: auto-retrato de Amy, aos cinco anos e onze meses. Mostra a construção arredondada da figura humana, comum entre crianças ocidentais.

Segundo: Desenho de um homem, feito por um menino de Berdgdama, de sete anos, no sudoeste da África. Mostra a construção triangular da figura, típica da região.

Fonte: Cox, 2001 


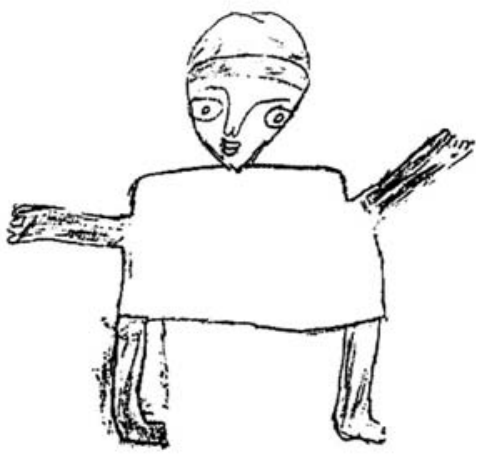

Figura 10: Este auto-retrato foi desenhado por um menino dos Iorubas, de dez anos, na Nigéria. O corpo retangular é uma característica dos desenhos produzidos em muitos países islâmicos do Oriente Médio e da África.

Fonte: Cox, 2001
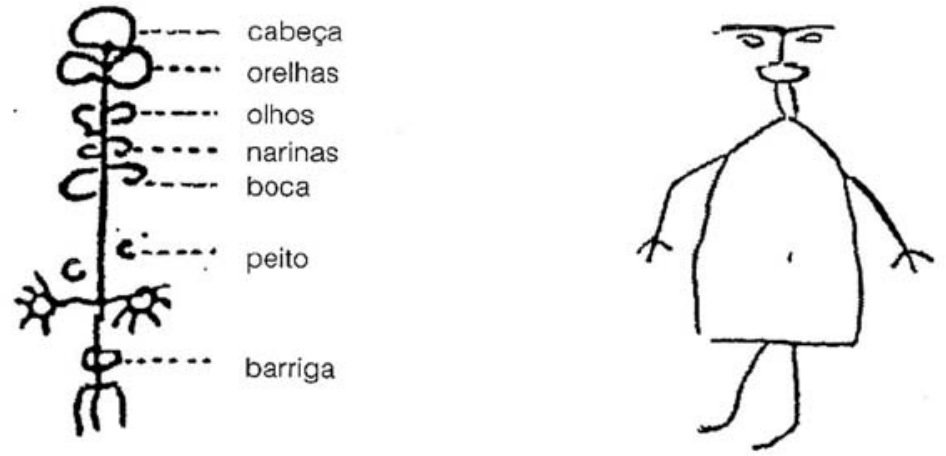

Figura 11: A primeira figura é a representação de uma mulher, feita por um menino indiano de seis anos. Todas as partes do corpo foram enfileiradas ao longo da linha da figura. O segundo é o desenho de uma mulher feito por uma menina iraniana de sete anos. Não há linha de limite englobando os traços faciais da figura.

Fonte: Cox, 2001 

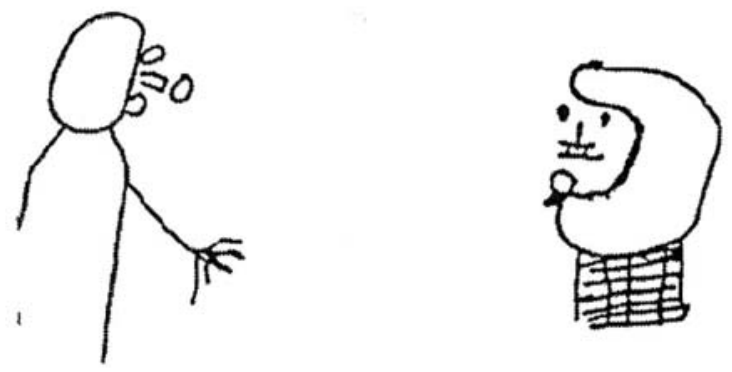

Figura 12: Estas foram desenhadas por crianças africanas de nove anos e mostram um perfil misto. A cabeça está de perfil; os traços faciais são separados da cabeça e mostrados com o rosto de frente.

Fonte: Cox, 2001

Como auxiliar a criança para desenhar:

- Estimular o contato com o desenho (pais x filhos);

- "Levar a linha pra passear", tornar a atividade mais subjetiva;

- Oferecer lápis - substituindo o giz de cera (esse proporciona maiores detalhes);

- Questioná-la sobre o assunto focado - instigar (assim iremos ajudar/auxiliar a criança a esclarecer para si mesma, o que não sabe e a enfrentar os problemas de representação);

- Enfrentar e derrotar a nossa própria dificuldade em orientar para o desenho. "[...] o professor deve certificar-se de que tudo o que é ensinado serve para finalidades criativas" (LARK-HOROVITZ, apud COX, 2001, p.242-243), procurando realizar a crítica e desafios de forma construtiva e interessante.

Atividades promovidas pelos professores, criativamente: Tomamos como exemplo a atividade desenvolvida pela professora Grant Cooke (1986). O intuito da sua atividade era promover algumas convenções básicas do desenho sem sacrificar o objetivo das crianças quanto à criatividade e autoexpressão. 
"Fritando Ovo" foi uma atividade onde a professora trouxe à sala de aula um fogão e fritou ovos com os alunos. Após, os alunos auxiliaram a professora, que desenhava no quadro, com dicas sobre as formas vistas na composição. Posteriormente, cada aluno realizou o seu próprio desenho, tendo registrado visualmente várias possibilidades e formas da composição.
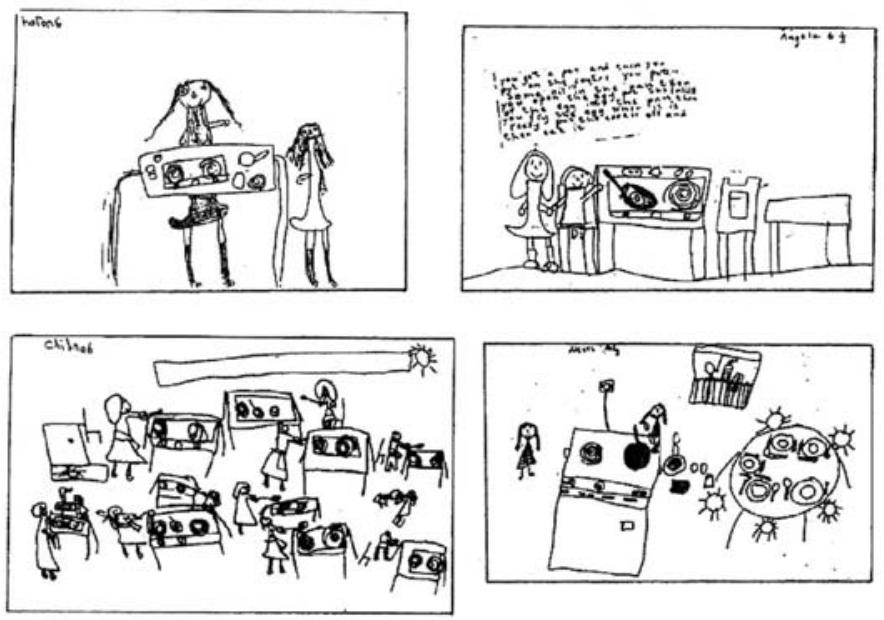

Figura 13: Desenhos sobre o tema "fritando um ovo", feitos por crianças de seis a sete anos de idade.

Fonte: Cox, 2001

"Eu sou uma bicicleta mágica e posso ajudar você", foi outra atividade desenvolvida pela professora que Cox (2001) relata em seu livro. Da mesma forma que "Fritando Ovos", ela trouxe uma bicicleta para a sala. Porém, ao concluírem o desenho no quadro juntamente com a professora, foi solicitado a um dos alunos, que retirasse um papel que estava dentro do cesto da bicicleta e que continha a seguinte frase: "Eu sou uma bicicleta mágica e posso ajudar você!". Sendo assim, a professora sugeriu que os alunos desenhassem uma aventura que pudesse ser realizada a partir dessa bicicleta mágica. Podemos perceber que pelo fato de elas terem participado ativamente com a professora durante o processo do desenho, as crianças conseguiram captar muitos detalhes da bicicleta e que muitas vezes passam despercebidos ao nosso olhar. 

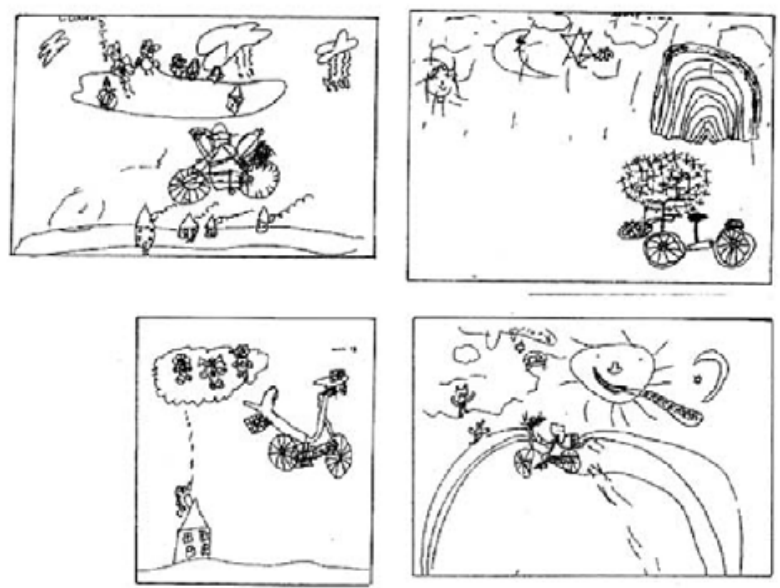

Figura 14: Desenhos de uma bicicleta mágica, feitos por crianças de cinco a seis anos.

Fonte: Cox, 2001

“[...] a vantagem é que o peso de saber como desenhar certo objeto é retirado e as crianças ficam livres para incorporá-lo em seu trabalho expressivo e imaginativo" (COX, 2001, p.248).

A nossa maior dificuldade, enquanto adultos, é "livrar-nos" dos estereótipos já pré-estabelecidos. Há uma repulsa em relação ao novo. Para que não venhamos a transformar os nossos educandos nesses sujeitos menos "elásticos" devemos nos precaver, propondo atividades interessantes e instigantes, em que eles venham a manter uma constante em relação ao novo saber. Segundo Piaget (mas a citação é de Munari... seria Piaget apud Munari???), o período ideal para isso são nos primeiros anos de vida do sujeito.

Sabemos que aquilo que uma criança de tenra idade memoriza permanecerá para a toda a sua vida. É por isso que podemos ajudar a criar indivíduos com uma mentalidade elástica e pronta a resolver todos os problemas que alguém pode ter na vida: desde encontrar um emprego até projetar sua própria casa ou educar os filhos. (MUNARI, 2002, p. 235-236). 
Munari (2002) nos sugere, entre tantas outras possibilidades para o desenvolvimento da comunicação verbal e visual e comportamento social, que as crianças até os três anos de idade tenham contanto com jogos e brinquedos adequados. "Nessa idade, ela memoriza os frutos das experiências sensoriais do ambiente que a rodeia. Seus receptores sensoriais funcionam todos ao mesmo tempo, ou seja, ela tem uma percepção global do ambiente em que vive" (p.237).

É nessa fase que tudo o que se faz e se aprende fica registrado para a vida a adulta, podendo-se resgatar as informações quando for necessário. Nos casos oportunos, serão estabelecidas relações com o que já sabe/observou, facilitando a sua compreensão. $\mathrm{O}$ autor ainda afirma que, se ocorrer a memorização desses fatos na infância corretamente, o sujeito tende a ser criativo e terá menos dificuldade em resolver diferentes tipos de situações.

$\mathrm{O}$ autor nos traz um exemplo bastante interessante. A construção de um livro, onde o sujeito possa ver, a sentir e interagir, criando diferentes possibilidades e situações. "O jogo ou brinquedo deve estimular a imaginação, e não vir pronto ou acabado (como acontece com algumas miniaturas perfeitas de automóveis), pois isso limita a participação da criança" (MUNARI, 2002, p.242). Para o autor, o jogo/brinquedo ideal, é aquele que permite à criança entendê-lo sem muitas explicações, e ir descobrindo-o no momento em que começa a manuseá-lo.

Ocorrem casos em que o próprio adulto, às vezes, ao manter contato com esse jogo/brinquedo "mais simples" encontra mais dificuldade do que a própria criança, pelo fato de ter excesso de cultura armazenada, não assimilando, assim, a novidade que lhe é apresentada. Com isso, acaba por recusar a tarefa para evitar o constrangimento e não se sentir inferiorizado perante os outros. Munari (2002) até sugere que se desenvolvam atividades didáticas com os próprios adultos, para afastarem os preconceitos, pois ele acredita que uma pessoa que já traz um bloqueio da infância fica "fossilizada" e irrecuperável.

E para complementar esse pensamento, o autor acrescenta:

Seria necessário treinar e habituar os adultos a compreenderem as crianças. Um antigo provérbio chinês diz que a única 
constante no mundo é a mudança. Se alguém procura detêla, detém-se a si mesmo e envelhece mal. Até uma certa altura, os adultos deveriam ensinar as crianças, mas depois seria melhor que aprendessem com elas a conhecer o mundo o mundo real, não o mundo artificial dos negócios. (MUNARI, 2002, p. 245).

Para podermos exigir que as crianças desenvolvam o desenho, a sua criatividade, devemos nos libertar do mundo lógico que nos circunda vinte quatro horas. Como vamos exigir das crianças que desenvolvam algo novo e que em nós mesmos causa constrangimento quando somos solicitados a fazê-lo? Precisamos refletir mais sobre as nossas próprias ações e possibilidades de propostas a serem trabalhadas com os nossos educandos. Somos responsáveis, em parte, pelo desenvolvimento desses futuros profissionais e antes de tudo, sujeitos.

\section{Notas}

'Formada em Artes Visuais (Bacharelado e Licenciatura) e Mestre em Educação pela Universidade Federal de Santa Maria. Atuou como docente na UFSM, UNOESC (Xanxerê, Joaçaba e São Miguel do Oeste) e atualmente na UNOCHAPECO, nos cursos de Artes Visuais e Arquitetura.moremar@unochapeco.edu.br

\section{Referências}

ALENCAR, Eunice M. L. S. Criatividade. Edit. Edunb, Brasília, 1993. ARNHEIM, Rudolf. Arte \& percepção visual: uma psicologia da visão criadora. 13. ed. São Paulo: Pioneira, 2000.

COX, Maureen. Desenho da criança. São Paulo: Martins Fontes, 2001.

DALTO, Darlene. Processo de criação. São Paulo: Marco Zero, 1993.

DE MASI, Domenico. Criatividade e grupos criativos: descoberta e invenção. Vol. I. Rio de Janeiro: Sextante, 2005. 
FERRAZ, Maria Heloíza C. de T. \& FUSARI, Maria F. de Resende. Metodologia do ensino de arte. São Paulo: Cortez, 1999.

GARDNER, Howard. Mentes que criam: uma anatomia da criatividade observada através das vidas de Freud, Einstein, Picasso, Stravinsky, Eliot, Graham e Gandhi. Porto Alegre: Artes Médicas, 1996.

As artes e o desenvolvimento humano. Porto Alegre: Artes Médicas, 1997.

Arte,mente e cérebro: uma abordagem cognitiva da criatividade. Porto Alegre: Artes Médicas, 1999.

HSUAN-AN, Tai. Desenho e organização bi e tridimensional da forma. Goiânia: UCG, 1997.

MORENO, Márcia. A teoria das inteligências múltiplas e sua relação com o processo de ensino e aprendizado do desenho: um estudo com adolescentes. 2005. 175 f. Dissertação (Mestrado em Educação) Universidade Federal de Santa Maria, Santa Maria, 2005.

MUNARI, Bruno. Das coisas nascem coisas. São Paulo: Martins Fontes, 2002.

OSTROWER, Fayga. Criatividade e processos de criação. Petrópolis: Vozes, 1987.

PILLAR, Analice D. Desenho e construção de conhecimento na criança. Porto Alegre: Artes Médicas, 1996. 
The drawing: a education process, learning and creative process development

\begin{abstract}
This research aims at to justify the importance of the drawing as language for the evelopment of the citizen's creative process, also reflecting, this magnifying of the creativity, in the grown ups. By this way, in elapsing of the text, some situations/possibilities, brought for some authors as well as of my own trajectory are presented as professor.
\end{abstract}

Keywords: creativity, crawing; educat.

Recebido em abr. de 2008

Aceito em jul. de 2008 
